\title{
Creative-digital diagnostics and reflexive development of school students in the course of studying Natural Sciences
}

\author{
Sergei Yurievich Stepanov ${ }^{1 *}$, Pavel Alexandrovich Orzhekovskiy ${ }^{2}$, and Inna Borisovna \\ Mishina $^{2}$ \\ ${ }^{1} \mathrm{MCU}$, Institute of Pedagogy and Psychology of Education, Department of Psychology, Moscow, \\ Russia. \\ ${ }^{2}$ Moscow Pedagogical State University, Institute of Biology and Chemistry, Department of Natural \\ Science Education and Communication Technologies, Moscow, Russia
}

\begin{abstract}
The authors of the article raises an issue that is relevant from the perspective of modern education connected with difficulties of using the results of psychological diagnostics of students' creative thinking carried out with the help of traditional testing techniques within the framework of the actual learning process. To address this issue, it is recommended to use the solutions suggested by the "forming" and "reflexive" approaches to this problem and conduct a synthesis of these two approaches using modern digital technologies. This way, it will provide us with an opportunity to turn developing (forming) procedures into diagnostic and turn diagnostic means into developing. Such a conceptual and technological symbiosis allowed us to create a computer networking system "CREO DATUM" enabling its users to carry out creative-digital diagnostics and psycho-pedagogical support of reflexive development of students' creative potential at the same time based on the material of one of the natural sciences taught within the school curriculum, namely chemistry. This system includes a database of domain-specific creative tasks by solving which students demonstrate their thinking abilities; digitalization of this process in the online mode allows teachers to monitor and assess the dynamics of such parameters of their creative potential as divergence and criticality. This tool enables the teacher and student to predict the area of future development promptly and select further creative tasks on the subject via "CREO DATUM" taking into consideration the strengths and weaknesses of previous creative efforts. Experimental testing of the "CREO DATUM" system allowed us to categorize the students who took part in the research. Four groups have been identified: children with high creative potential, ones with low creative potential, divergents, and analysts. Methodological recommendations have been developed for each category of students based on the material of a natural science subject aimed at psychological and pedagogical support of their development.
\end{abstract}

\footnotetext{
*Corresponding author: stepanovs@mgpu.ru
} 
Keywords: diagnostics, development, creative thinking, reflection divergence, criticality.

\section{Introduction}

In modern psychological and didactic works [1], methods of diagnostics and means of developing intellectual, and even more so, creative abilities based on a certain academic discipline, are usually deliberately separated as fundamentally different methodological tools [2]. At the same time, high emphasis is placed on validation and increasing the reliability of diagnostic measurements based on tasks with content related to academic disciplines as well as their correlation with the results of widely recognized creativity tests. Such "separation" creates difficulties, in the first place for practicing teachers, when based on such diagnostics they are trying to choose the most helpful ways of psycho-pedagogical correction or further development of aptitudes possessed by modern school students [3] using training activities related to the content of certain academic disciplines, especially when it has to be done in the context of digitalization of education $[4,5]$ and an increase of the share of distance learning $[6,7]$.

In Russian science, there have already been a few attempts at overcoming this "psychodidactic gap". For instance, using P.Ya. Galperin's theory and method of stage-by-stage formation of mental actions and concepts [8], N.F. Talyzina and Yu.V. Karpov [9] developed principles and techniques of diagnostics of intellectual abilities relying on "reconstruction" of the process of their formation. S.Yu. Stepanov and E.P. Varlamova [10] involved return movement from diagnostics to development, when the very diagnostic procedures and ways of interpreting their results turn into psycho-pedagogical means of prompting the examined students to engage in creative self-development. This approach to psychological measurements was called reflexive diagnostics.

The conceptual and methodological symbiosis of these approaches is now possible thanks to the usage of digital technologies, which can provide teachers with substantial assistance both in the choice of the most relevant creative tasks with academic content and in the analysis of results obtained in the course of diagnostics, which represents, on the one hand, a method of fixation of the achieved development level and, on the other hand, basis for determining "the area of upcoming development" and set of criteria for selecting new learning activities within the boundaries of this area.

\section{Methods}

The database of creative activities including tasks based on the school course of chemistry [11] used for both developments of students' creative thinking and its diagnostics was integrated into the computer networking system "CREO DATUM" pursuing developing and diagnostic goals [12], which was specially designed with financial support from the Russian Foundation for Basic Research (grant no. 19-29-14136mk).

During a class, with the help of their gadgets (smartphones, tablets, laptops, or personal computers) students can register in the "CREO DATUM" system. After that, they get a creative task and start working on it, recording the results of their reflections (i.e., their ideas and solutions) into a special digital form. The system itself orients students towards the consistent accomplishment of the task and critical assessment of their solutions. "CREO DATUM" executes online processing of the recorded and digitized answers and creates diagrams and graphs reflecting the development of creative thinking for each student. Reflexive analysis of the student's indicators of their creative development carried out by the 
teacher and student helps them to create a trajectory of the following educational steps both in terms of learning the corresponding subject and building up one's own creative potential.

"CREO DATUM" system allows its users to digitize and analyze the dynamics of mental actions of divergent (D) and criticality (C) nature. The Fibonacci sequence is used for quantitative assessment of the indicated creativity parameters and their further digitizing. This allows us to take into account the uneven increase of the degree of complexity and thinking efforts made by students in the course of looking for solutions to creative tasks based on the school course of chemistry. To calculate the parameter of divergence, the following formula is used: $D=\sum_{i=1}^{d} \times F_{i}$, where $D$ represents the total divergence of thinking, $d$ - the number of answer options, and $F_{l}$ - the corresponding number in the Fibonacci sequence. To calculate the parameter of criticality, the formula is the following: $C=\sum_{i=1}^{j} \times \sum_{m=1}^{n} \times F_{i m}$, where $C$ represents general criticality, $j$ - the number of answers where the student has found some drawbacks, $n$ - the number of identified drawbacks in the $i$ answer variant, $F_{i m}-$ the corresponding number in the Fibonacci sequence for the $m$ drawback in the $i$ answer.

One of the important parameters in the course of the assessment of the student's creative actions is the balanced development of the divergent and criticality aspects of creative thinking. Development is balanced if the values of thinking criticality and divergence expressed in points are commensurate. To identify the area of balanced development, the balance ratio has been introduced: $B=C / D$. This ratio shows the relation between criticality and divergent actions taken by the student in the course of solving a creative task, which means that it reflects the level of balance in creative thinking development. Based on a statistical analysis of experimental data, the area of students' balanced development in the sphere of creative thinking has been identified: $0.6 \leq B \leq 1.4$.

\section{$3 \quad$ Results}

The experimental testing of the "CREO DATUM" system for a quantitative appraisal of the development of students' creative thinking in the course of solving creative tasks in Chemistry lessons was implemented with the participation of 113 general education school students living in Moscow including 54 students of the 8th grade and 59 students of the 9th grade. The examinees were offered seven creative tasks based on the school course in chemistry. Following the results of the processing of 565 reports, the system created individual trajectories of creative thinking development for each student.

In the course of processing of the obtained data, four categories of students were identified: 1) with low creative potential - when both divergent and critical thinking are poorly expressed (when the values of $D$ and $C$ are close to zero); 2) with high creative potential - with strongly expressed and balanced indicators of creative thinking; 3) "divergents" - with high indicators of divergent thinking but low criticality; 4) "analysts"with high indicators of critical thinking but low divergence. As illustrated by analysis of the students' responses provided in the course of accomplishing creative tasks, the percentage distribution of students into the following groups has been identified (Table 1).

Table 1. Classification of students based on the nature of their creative thinking.

\begin{tabular}{|c|c|c|c|}
\hline $\begin{array}{c}\text { With low creative } \\
\text { potential }\end{array}$ & $\begin{array}{c}\text { With high creative } \\
\text { potential }\end{array}$ & "Divergents" & "Analysts" \\
\hline $7 \%$ & $46 \%$ & $41 \%$ & $69 \%$ \\
\hline
\end{tabular}




\section{Discussion}

Table 1 shows that $7 \%$ of school students have not scored a single answer, which testifies to their lack of experience in the sphere of creativity. In this case, the teacher should use the "CREO DATUM" system to select simple creative tasks and review the suitable reflexive and heuristic techniques that are aimed at encouraging creative activities undertaken by students and analysis of their thinking efforts in as much detail as possible.

$46 \%$ of students possess high creative potential which manifests itself in strongly pronounced critical and divergent aspects of thinking and the balance between them. Working with such children, it is necessary to improve absolute indicators of their creative thinking consistently by including further creative activities in the learning process. If there is a deviation of the creative thinking indicator from the balance area, it is necessary to modify the creative development trajectory of the student by offering them tasks from the "CREO DATUM" system focused on compensation for the weakly manifested parameter (divergent or critical thinking).

$41 \%$ of the students offered a lot of solutions in the course of doing creative activities but did not conduct their analysis and creative assessment, showing predominantly divergent thinking. Therefore, when the teacher continues their work with the students, it will be necessary to focus on the depth of elaboration of each solution. For this purpose, the teacher uses the "CREO DATUM" system to assign the students a task which, for example, offers a certain solution to the problem, and the students are asked to conduct a detailed analysis of the advantages and disadvantages of this solution.

The remaining $6 \%$ of the students, who suggested few solutions but in detail described the drawbacks and difficulties of their implementation were qualified as "analysts". Working with such students, it is reasonable to focus on the divergent component of creative thinking. To this end, the system "CREO DATUM" can suggest a task where the student has to offer as many solutions to a problem as possible.

Accordingly, the opportunity to determine the next sphere of the student's development allows the teacher to plan individual work on developing student's creative abilities, while analysis of several parameters of creative thinking at the same time enables educators to influence its components in a targeted way for their further development.

In conclusion, we would like to thank the Russian Foundation for Basic Research for providing financial support of this article (grant no. 19-29-14136mk) and point out that creative-digital diagnostics of students based on academic disciplines with the help of the "CREO DATUM" system allows the teacher not only to identify the initial level of students' creative potential but also compile individual recommendations in the online mode and provide reflexive support of students' creative thinking by selecting personally-oriented creative tasks in corresponding subjects. This approach will allow teachers to enhance students' interest and their motivation for accomplishing untypical tasks. The potential for further development and scaling up of the "CREO DATUM" system includes the incorporation of creative activities based on other school subjects in its database and expanding the scope of diagnosed creative thinking indicators. The crucial task of improving this system is connected with developing psycho-pedagogical tools integrating experimental and laboratory-based creative tasks involving the material of natural sciences as well as artificial intelligence and big data technologies.

\section{References}

1. S. Kurt, Instructional Design, in Educational Technology (2016). Accessed on: December 09, 2020. [Online]. Available:

https://educationaltechnology.net/instructional-design/ 
2. K. Haim, Praxisder Naturwissenschaften Chemieinder Schule, JAHRGANG, 4(62), 34-37 (2013)

3. A. J. Nicholas, Preferred Learning Methods of Generation Z (2020). Accessed on: August 25, 2020. [Online]. Available: https://digitalcommons.salve.edu/fac_staff_pub/74/

4. M.A. Camilleri, A.C. Camilleri, Tech Know Learn, 22, 65-82 (2017). https://doi.org/10.1007/s10758-016-9287-7

5. T. Hillman, A. B. Rensfeldt, J. Ivarsson, Learning, Media and Technology, 45(1), 7-16 (2020). https://doi.org/10.1080/17439884.2020.1683748

6. J. Bond, K. Dirkin, Online Journal of Distance Learning Administration, 21(4), Winter (2018). Accessed on: October 25, 2020. [Online]. Available: https://www.westga.edu/ distance/ojdla/winter214/bond_dirkin214.html

7. B. Williamson, R. Eynon, J. Potter, Learning, Media and Technology, 45(2), 107-114 (2020). https://doi.org/10.1080/17439884.2020.1761641

8. P. Ya. Galperin, Osnovnye rezultaty issledovanii po probleme "Formirovanie umstvennykh deistvii i ponyatii" [The main research results on the problem "Formation of mental actions and concepts"]. Abstract of a PhD thesis in Psychology (Lomonosov Moscow State University, Moscow, 1965)

9. N.F. Talyzina, Yu.V. Karpov, Pedagogicheskaya psikhologiya. Psikhodiagnostika intellekta [Pedagogical psychology. Psychodiagnostics of intelligence] (Moscow, Moscow State University Publishing, 1987)

10. E.P. Varlamova, S.Yu. Stepanov, Voprosy Psikhologii, 5, 28-43 (1997)

11. P.A. Orzhekovskii, V.N. Davydov, N.A. Titov, Eksperimentalnye tvorcheskie zadachi po neorganicheskoi khimii: kniga dlya uchashchikhsya [Experimental creativy tasks on organic chemistry] (Moscow, Arkti, 1998)

12. P.A. Orzhekovskii, S.Yu. Stepanov, I.B. Mishina, Nepreryvnoe Obrazovanie, 21 vek, 3 (31) (2020). https://doi.org/10.15393/j5.art.2020.6044

13. E. P. Torrance, The Creative Child and Adult Quarterly, 3, 148-158 (1980)

14. J.P. Guilford, American Psychologist, 14 (1959)

15. K.K. Urban, International Education Journal, 6(3), 272-280 (2005) 